\title{
Ethnobotanical Studies in India on the Medicinal and Aromatic Plants
}

Gopal Dixit*

Botany Department, Upadhi PG College, MJP Rohilkhand University, Pilibhit, India

\section{Editorial}

Biodiversity provides number of essential services naturally like crop production and protection, soil fertility, nature conservation with the aim of availability of natural resources to all living beings. Indian Ethnobotanical study is as old as human civilization and is one of the richest cultural traditions associated with the diverse uses of medicinal and aromatic plants. Many ancient religious literatures show a great heritage of herbal treatments. Several ethnic groups and rural people have possessed vast experience of different usage of medicinal and aromatic plants growing nearby them in the treatment of many human and veterinary ailments. They developed their own system of knowledge pertaining to sustainable use of plant resources, animals and natural wealth through repeated experimentation and by trial and error methods. Men of olden times were wise enough and had reliable know how about several plant to fulfill their daily needs of life. Among the usage of plants, medicinal plants constitute the main group.

Medicinal and aromatic plants constitute most significant group of plants in the welfare of living beings. Most of these plants are found growing wild and collected by different ethnic and rural people of our country. They used them freely for the treatment of various human and animal ailments, on the basis of their ancestral knowledge and beliefs. They know medicinal usage of several wild plants growing nearby them for the sure cure of different diseases. But over exploitation of these natural resources by so called civilized world is leading to their vulnerability day by day. Hence, cultivation and conservation of naturally growing medicinal and aromatic plants is also the need of hour to ensure uninterrupted supply of quality raw drugs, a pre requisite for quality control and availability in the manufacturing of finished plants based drugs. Not only this, it also provides employment at grass root level both in agriculture and rural sector. It has been estimated that in India, only 12-12 million people are directly or indirectly involved in medicinal industry based on plants. Keeping in mind these facts, it is possible for India to involve more and more rural people in large scale cultivation of medicinal and aromatic plants to replace conventional farming for good income and employment generation. These practices provide sufficient raw material for plant based pharmaceutical industries to produce quality ayurvedic drugs and also play a major role in the market of universal herbal drugs and neutraceuticals and cosmaceuticals [1].

\section{Resources of Medicinal Plants}

In India most of the demand of medicinal and aromatic plants is fulfilled from wild resources especially from the forests both by tribal and industries. To maintain the uninterrupted supply of this raw material to domestic plant based pharmaceutical industries in India, it is necessary to undertake large scale cultivation of high value medicinal plants to replace traditional agriculture. Large scale cultivation of most valued medicinal plants is the only alternative to minimize heavy destruction and uncontrolled harvesting from wild natural resources. For the said purpose, central and state governments have banned the trade and export of 29 such rare and threatened plants. Conservation and sustainable harvesting of these endangered plant sources, including medicinal and aromatic plants has been kept on major priority, in order to check heavy loss to plant diversity.
According to recent investigative study by the Ministry of Environment of Forests (MoEF), Government of India, under All India Coordinate Research Project on Ethnobiology (AICRPE), the ethnic communities in India are using more than 10000 wild plants in various therapies, edible and other miscellaneous uses. Among these, 800 plants are used for different medicinal purposes by the Indian tribal people [2].

\section{Ethnic Knowledge}

Ethnic people possess a deep and vast knowledge about the traditional knowledge system world over which has been a gift to civilized population. This knowledge is based on generation long experience of tribal people which has been passing from generation to generation in a very natural way. In fact it is the "Green Economy". This knowledge is community specific functional knowledge generated, preserved and carried over by these ethnic and rural people from generations and based on interactions, observations and experiences. Ethnic knowledge serves as a natural tool to encounter different dayto-day requirements like food, shelter, cloth of living beings. Apart from it, ethnic communities are also providing sustainable herbal and natural solutions for the various human and veterinary ailments which can create possibilities of income generation to rural and unorganized sector for alleviation of poverty. According to estimation approximately $80 \%$ of world's population depends upon plants as primary medicines.

Traditional knowledge Digital Library (TKDL) is developed by Government of India in order to preserve all type of traditional knowledge like Ayurveda, Unani, Siddha and Yoga and prevent any possible misuse of this ethical knowledge. The chief motive of this library is to preserve and protect the ethical knowledge of India from any sort of exploitation as bio piracy and unethical patents.

\section{Resources of Aromatic Plants}

Like medicinal plant resources aromatic plants of India also have an ancient history in human civilization. Trade of aromatic plants from India through sea passage is very old as mentioned in different religious and historical literature. Various spices like pepper, cardamom, ginger, and sandal wood were taken from Indian western coast and exported to different countries of the world. According to a survey of aromatic plants of India, approximately 3000 plant species of 60 main families, have the aromatic value which are using in different aroma purposes like in medicines, soaps, cosmetics, perfumes, pharmaceuticals, textiles,

${ }^{*}$ Corresponding author: Gopal Dixit, Head of Botany Department, Upadhi PG College, MJP Rohilkhand University, Pilibhit, 262001 India, Tel: +919412196698; E-mail: gopaldixit2k@yahoo.com

Received January 22, 2019; Accepted January 23, 2019; Published January 30, 2019

Citation: Dixit G (2019) Ethnobotanical Studies in India on the Medicinal and Aromatic Plants. J Bioanal Biomed 11:e161. doi:10.4172/1948-593X.1000e161

Copyright: (02019 Dixit G. This is an open-access article distributed under the terms of the Creative Commons Attribution License, which permits unrestricted use, distribution, and reproduction in any medium, provided the original author and source are credited. 
Citation: Dixit G (2019) Ethnobotanical Studies in India on the Medicinal and Aromatic Plants. J Bioanal Biomed 11:e161. doi:10.4172/1948$593 X .1000$ e161

confectionary, freshners, deodorants, paints, disinfectants, insecticides and pesticides etc. [3].

\section{Conclusion}

In order to cope up with increasing demand of medicinal and aromatic plants world over especially in pharmaceutical and nutraceutical industries, it is necessary for our country to maintain a balance between availability and supply. Hence it is a need of hour to develop appropriate technologies to fulfill present and future demands in most sustainable and balanced ways. One of the effective methods in this regard is to implement commercial cultivation practices for most of medicinal and aromatic plants. Different government and non-government agencies have successfully developed commercial cultivation practices for many wild species. Agriculture and plant scientists are relentlessly working on preservation of most wild medicinal and aromatic plants through cultivation, under various research projects. This is the only workable solution for the conservation of naturally growing medicinal and aromatic plants world over, and on the other hand it will provide better monetary assignments to all the farmers, employability to rural poor and uninterrupted supply to herbal industries as well.

\section{References}

1. Dixit G (2009) Indigenous/traditional medicines: challenges and bottlenecks. IASTAM, Thimpu, Bhutan.

2. Dixit G, Vakshasya S (2013) Prospects of forest products and cottage industries in tribal economic upliftment of sub Himalayan terai Region of Uttar Pradesh, In: Agri Business and Rural Management, Mittal Publication, New Delhi pp. 507-516.

3. Pushpangdan P, ljinu TP, George V (2013) Opportunities for ethnobotanical studies on medicinal and aromatic plants in India. Etnobot 25: 22-32. 